\title{
Market Performance Study of Air Transportation in China Based on DEA Model
}

\author{
Yuefang $\mathrm{Xu}^{1, \text { a) }}$ and Jiawei $\mathrm{Zou}^{2}$, b) \\ Civil Aviation College of Nanjing University of Aeronautics \& Astronautics, Nanjing, 210000, China \\ a)xuyf@nuaa.edu.cn, b) 1263021554@qq.com
}

\begin{abstract}
In recent years, the issues of efficiency for civil aviation industry and how to increase the efficiency for civil aviation industry in china are very important. In macro aspect, this paper analyzes the empirical data of civil aviation industry in china from 2000 to 2016 based on DEA model; in micro aspect, this paper analyzes the efficiency of ten airlines in china in 2010 and 2014 based on DEA model. This work is significant to improve the efficiency of the whole industry and airline.
\end{abstract}

Key words: air transportation industry, market performance, efficiency, DEA model.

\section{INTRODUCTION}

At present, China's civil aviation industry has been the second largest in the world, the flight regularity rate of major airlines in 2015 was merely $68.9 \%$. Compared with the total transport turnover, the revenue of civil aviation and the output, the investment of China's flight routes, aircraft fleet size and the number of staff has a lot of redundancy, reflecting the low efficiency of civil aviation transportation industry. Therefore, it is urgent to improve the market performance of China's civil aviation industry at the present stage.

All the mentioned papers merely evaluate the efficiency by taking an airline as a unit instead of taking mergers among airlines into consideration.

\section{MARKET PERFORMANCE DEFINITION AND MEASUREMENT METHODS}

\section{Definition of Market Performance(MP)}

MP refers to the final economic achievements of a certain industry in terms of price, cost, output, profit, product quality and technological progress through a certain market structure. [1]

\section{Market Performance Measurement}

According to the definition of MP, it can be seen that market performance can be measured from the perspective of economic indicators and efficiency. Therefore, market performance measurement methods consist of Single Factor Analysis and Frontier Analysis. Among them, the Frontier Analysis method includes Data Envelopment Analysis and Stochastic Frontier Production Function.

Data Envelopment Analysis (DEA) is a non-parametric method based on mathematical programming. The principle is to keep the input and output of the decision unit constant and use the linear programming method to construct the non-parametric frontier of observation data, and then project each decision unit onto the front face. By 
comparing the extent to which decision elements deviate from the frontier, their relative effectiveness, relative efficiency, is evaluated [2].

The stochastic frontier production function method needs to artificially set the production function and the random disturbance term, so it is very likely to be affected by subjective factors. The Data Envelopment Analysis method doesn't need to explicitly specify the quantitative relationship between input and output, so it can effectively avoid the influence of subjective factors. Therefore, the following of the article will use the DEA model to analyze the efficiency.

\section{DEA MODEL OVERVIEW}

The common DEA model includes the CCR model and the BCC model. The CCR model is applicable to the case where the scale returns are constant, and the BCC model is applicable to the situation where the scale returns are changed.

\section{CCR-I Model}

Assume that there is one enterprise in a certain industry, and each enterprise uses the $M$ kinds of inputs to produce $\mathrm{N}$ kinds of outputs, and the input and output of the i-th enterprise, that is, the ith decision-making unit can use input vectors $\vec{x}_{i}=\left(x_{1 i}, x_{2 i}, \cdots, x_{M i}\right)^{T}$ and output vectors $\vec{y}_{i}=\left(y_{1 i}, y_{2 i}, \cdots, y_{N i}\right)^{T}$. If $\vec{u}$ and $\vec{v}$ represent input, output weight vector, so the relative efficiency of the $i$ th decision unit is $\theta_{i}=\frac{\sum_{n=1}^{N} v_{n} y_{n i}}{\sum_{m=1}^{M} u_{m} X_{m i}}=\frac{\vec{v}^{T} \vec{y}_{i}}{\vec{u}^{T} \vec{X}_{i}}$. Obviously, the initial model can be formed as follows:

$$
\max _{\vec{u}, \vec{v}}\left(\frac{\vec{v}^{T} \vec{y}_{i}}{\vec{u}^{T} \vec{x}_{i}}\right)
$$

$$
\text { s.t } \frac{\vec{v}^{T} \vec{y}_{j}}{\vec{u}^{T} \vec{X}_{j}} \leq 1, j=1,2, \cdots, I \quad \vec{u}, \vec{v} \geq 0
$$

\section{BCC-I Model}

The BCC-I model adds a constraint to the CCR-I model $I_{1}^{T} \cdot \lambda=1$, a matrix $I_{1}$ indicating that the elements are all $I \times 1, I_{1}^{T} \cdot \lambda=1$ indicating that the sum of the constants in the constant vector $\vec{\lambda}$ is 1 . The specific model is as follows:

$$
\min _{\theta, \vec{\lambda}}(\theta) \quad \text { s.t. }-\vec{y}_{i}+Y \cdot \vec{\lambda} \geq 0 \quad \theta \cdot \vec{x}_{i}-X \cdot \vec{\lambda} \geq 0 \quad \vec{\lambda} \geq 0, \theta, i=1,2, \cdots, I
$$

The constraints of the BCC model are more stringent than those of the CCR model.

\section{AN EMPIRICAL ANALYSIS OF THE EFFICIENCY OF CHINA'S CIVIL AVIATION INDUSTRY}

\section{Analysis of the Efficiency of the Whole Industry of China's Civil Aviation}

(1) Selection of input-output index: Whether the choice of indexes is accurate or reasonable will directly affect the performance (DMU). [3] The input index is composed of airline mileage, terminal number of civil aircraft and number of airline employees. The total turnover of transportation is selected as the output index. Because the price of China's 
civil aviation industry cannot fully reflect the condition of the market, the civil aviation revenue is not chosen as the output index.

(2) Data sources: Data of transport comes from the books Analyze from the Statistics of Civil Aviation 2001-2016 and statistical data on the web site of the Civil Aviation Administration.

(3) Empirical analysis: In this paper, DEA SOLVER5.0 software is used to calculate the efficiency of China's civil aviation industry in $2000-2016$. Among them, the CCR-I model in the software helps to obtain the comprehensive technical efficiency (CRSTE). The BCC-I model obtains the pure technical efficiency value (VRSTE). T the scale efficiency value (SCALE) is derived from the separation of the comprehensive technical efficiency value from the pure technical efficiency value. Therefore, after arranging, the efficiency value of China's civil aviation industry in 2000 -2016 is shown in Table 1 below.

TABLE 1. Efficiency Value of China's Civil Aviation Industry in 2000 -2016

\begin{tabular}{lcccc}
\hline DMU & CRSTE & VRSTE & SCALE & Scale Revenue \\
\hline 2000 & 0.689 & 1.000 & 0.689 & irs \\
2001 & 0.740 & 1.000 & 0.740 & irs \\
2002 & 0.813 & 1.000 & 0.813 & irs \\
2003 & 0.763 & 0.978 & 0.780 & irs \\
2004 & 0.909 & 1.000 & 0.909 & irs \\
2005 & 0.898 & 0.999 & 0.899 & irs \\
2006 & 0.909 & 1.000 & 0.909 & irs \\
2007 & 0.955 & 0.994 & 0.961 & irs \\
2008 & 0.888 & 0.950 & 0.935 & crs \\
2009 & 0.948 & 1.000 & 0.948 & drs \\
2010 & 1.000 & 1.000 & 1.000 & drs \\
2011 & 0.971 & 0.977 & 0.994 & drs \\
2012 & 0.933 & 0.985 & 0.947 & drs \\
2013 & 0.929 & 0.947 & 0.981 & drs \\
2014 & 0.936 & 0.962 & 0.973 & drs \\
2015 & 0.953 & 1.000 & 0.953 & 0.962 \\
2016 & 0.962 & 1.000 & & \\
\hline
\end{tabular}

In order to make a clearer analysis of the changing trend of the efficiency of China's civil aviation industry, you can see Figure 1.

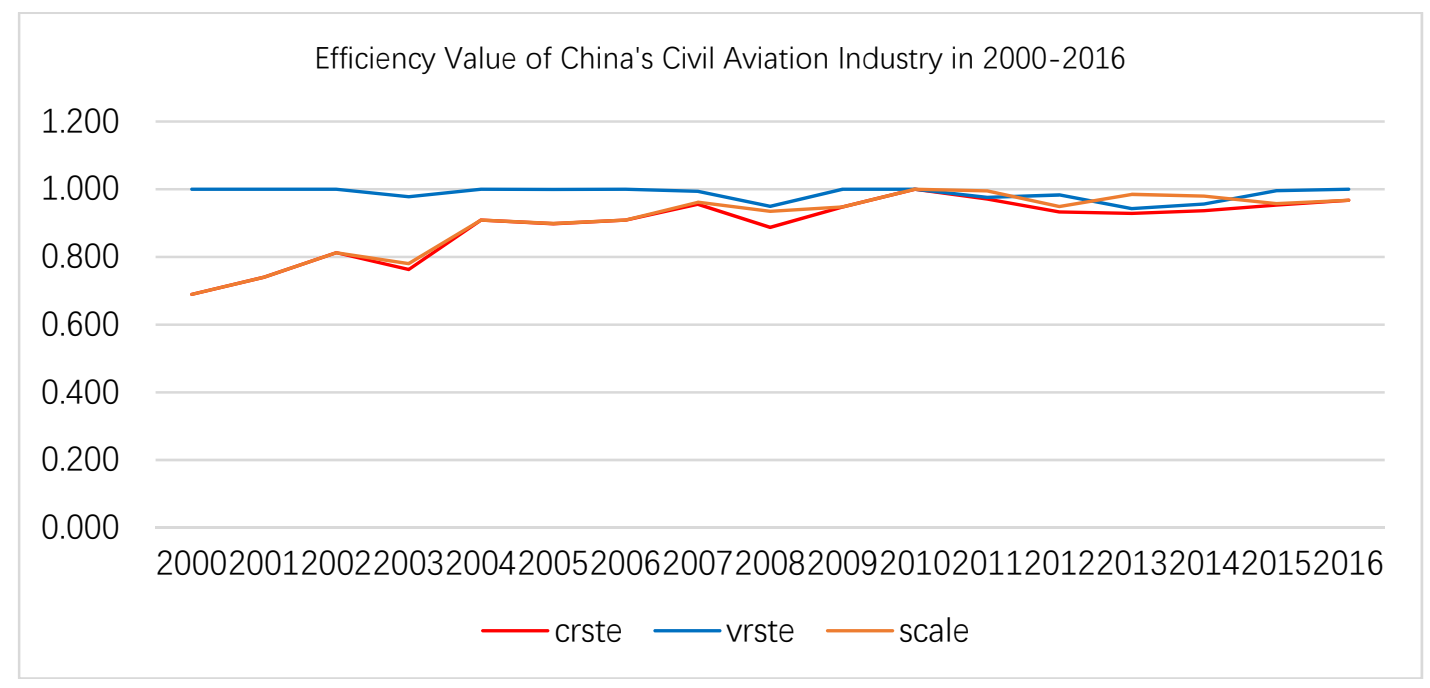

FIGURE 1.2000-2016 crste, vrste and scale value of China's civil aviation industry

From figure 1, we can draw the following conclusions: 
(1) From 2000 to 2010, the integrated technical efficiency fold line and the scale efficiency fold line are almost in coincidence, indicating that the scale efficiency dominates the change of integrated technical efficiency. From 2011 to 2016, integrated technical efficiency fold line, pure technical efficiency fold line and scale efficiency fold line intertwine with each other, illustrating that the pure technical efficiency and the scale efficiency jointly determine the change of integrated technical efficiency.

(2) The increasing use and improving management of new technology in the field of civil aviation contribute to the overall rise of integrated technical efficiency. During 2000 to 2002, the efficiency value presented an upward trend. The efficiency value in 2003-2004 was rapidly picked up and went beyond that in 2002. Between 2004 and 2007, the efficiency value was in a stable state. From 2007 to 2008, the efficiency value was declining. From 2008 to 2010 , the efficiency value was witnessed a continue increase and reached its peak in 2010 in the past 15 years. In 2010-2016, the efficiency value decreased at first and then recovered a little bit.

\section{Analysis on Operating Efficiency of Chinese Civil Aviation Enterprises and Airlines}

(1) Selection of Airlines: There are many civil aviation enterprises in China. If all airlines are selected as decision making units, it's impracticable to get all data. Therefore, this paper selects ten airlines as the 10 decision making units [4].

(2) Empirical Analysis: This paper selects China National Aviation Holding Company, China Eastern Airlines Corp. Ltd., China Southern Airlines Corp. Ltd., HNA Group, Shenzhen Airlines Co. Ltd., and Sichuan Airlines Co. Ltd., Xiamen Airlines Co. Ltd., Air China Cargo Co. Ltd., Shandong Airlines Co. Ltd., Spring Airlines Co. Ltd., the ten Airlines (companies) as the 10 decision-making units, and compares and analyses 2010 and 2014, with the highest efficiency of the whole industry and the most comprehensive data respectively, to obtain the comprehensive technical efficiency value, pure technical efficiency value and scale efficiency value of the 10 DMU by CCR-I and BCC-I models in DEA SOLVER5.0. The results are shown in table 2 and table 3 as follows:

TABLE 2. The Efficiency Value in 2010.

\begin{tabular}{cccc}
\hline DEU & CRSTE & VRSTE & SCALE \\
\hline China Airlines & 1.000 & 1.000 & 1.000 \\
Eastern Airlines & 0.900 & 1.000 & 0.900 \\
Southern Airlines & 0.757 & 0.937 & 0.808 \\
HNA Group & 0.971 & 1.000 & 0.971 \\
Shenzhen Airlines & 0.964 & 0.983 & 0.981 \\
Air China Cargo & 1.000 & 1.000 & 1.000 \\
Xiamen Airlines & 0.964 & 0.965 & 0.999 \\
Sichuan Airlines & 1.000 & 1.000 & 1.000 \\
Shandong Airlines & 1.000 & 1.000 & 1.000 \\
Spring Airlines & 1.000 & 1.000 & 1.000 \\
\hline
\end{tabular}

TABLE 3. The Efficiency Value in 2014

\begin{tabular}{cccc}
\hline DEU & CRSTE & VRSTE & SCALE \\
\hline China Airlines & 1.000 & 1.000 & 1.000 \\
Eastern Airlines & 0.803 & 1.000 & 0.803 \\
Southern Airlines & 0.807 & 1.000 & 0.807 \\
HNA Group & 0.906 & 1.000 & 0.906 \\
Shenzhen Airlines & 0.896 & 0.969 & 0.925 \\
Air China Cargo & 1.000 & 1.000 & 1.000 \\
Xiamen Airlines & 0.896 & 0.947 & 0.946 \\
Sichuan Airlines & 0.934 & 0.996 & 0.938 \\
Shandong Airlines & 0.931 & 0.936 & 0.995 \\
Spring Airlines & 1.000 & 1.000 & 1.000 \\
\hline
\end{tabular}

Compared to table above, we can conclude that: 
(1) The efficiency value of each airline in 2010 was obviously higher than that in 2014 , which verifies the conclusion of the analysis on efficiency of the whole industry, and also verifies that the ten airlines (companies) can represent the whole industry well.

(2) In 2010 and 2014, the CRSTE, VRSTE and scale value of China Airlines, Air China Cargo and Spring Airlines were all 1, which showed that the three airlines were in effective state in those three aspects. At the same time, Spring Airlines is a low-cost airline, which illustrated that low-cost airlines are quite efficient in fleet management and resource utilization.

(3) In 2014, China Airlines, Air China Cargo and Spring Airlines were effective in the CRSTE and scale value, while the other airlines were invalid. China Airlines, Eastern Airlines, Southern Airlines, HNA Group, Air China Cargo and Spring Airlines were effective in VRSTE, while other airlines were all invalid. Therefore, among those inefficient airlines, the invalid CRSTE of Eastern Airlines, Southern Airlines, HNA Group are caused by the scale inefficiency. And the invalid CRSTE of the four local airlines-Shenzhen Airlines, Xiamen Airlines, Sichuan Airlines and Shandong Airlines, are caused by VRSTE inefficiency and scale inefficiency.

\section{REFERENCES}

1. Liu Zhibiao. Economics of Industry[M]. Beijing, the China Machine Press,2015.

2. Ma Zhanxin. Data Envelopment Analysis Model and Method [M]. Beijing: Science Press, 2016.

3. Chen Hui. Research of Chinese Civil Aviation Industry Efficiency Using DEA Approach[D]. Hefei: Hefei University of Technology,2010.

4. Chen Yuxiu,Li Li, Zhao Dongwei. Research on Investment Efficiency Evaluation of Airlines in China[J].Friends of Accounting,2015,11:72-76. 